\title{
Online versus Traditional Learning: Outcomes of First Online Learning Experience
}

\author{
UZAIR ABBAS ${ }^{1}$, MEMOONA PARVEEN², AMBREEN ASHFAQUE ${ }^{3}$, RAMLAH NAZ $^{4}$, SIDRA ZAHEER ${ }^{5}$, ZAHEER AMJAD \\ 1-3 Lecturers, Department of Physiology, \\ ${ }^{4}$ Associate professor Department of Forensic Medicine, \\ ${ }^{5}$ Lecturer Institute of Medical Technology, \\ ${ }^{6}$ Assistant Professor, Department of Anatomy. Dow University of Health Sciences, Karachi \\ Correspondence to Dr. Uzair Abbas, e-mail uzair.abbas@duhs.edu.pk Cell: 0300-3280080
}

\begin{abstract}
Aim: To evaluate the learning outcomes of first experience with online learning in a medical college in Pakistan. Study design: Retrospective cross-sectional study

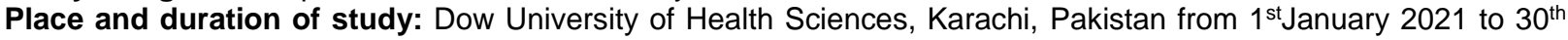
May 2021.

Methodology: This study compared the module exam scores of pre-clinical first-year MBBS students of the year 2019 (group A) and year 2020 (group B). Group A was taught in 2019 through the traditional method of teaching while group B was taught online in 2020.

Results: The mean score of group B online teaching was significantly higher than that of group A, studied through the traditional method in all three modules, foundation module, locomotor module, and blood module. Group B secured a significantly higher mean score than that of group A with a significant $p$-value of $<0.001,0.043$, and 0.001 respectively.

Conclusion: The score gained by online learners using virtual teaching methods was significantly higher than those who were taught by traditional method. The results of this study imply that using online educational teaching and learning can lead to the promotion of educational level and enhancement of score levels in students.

Keywords: Online learning, Traditional learning, Medical education
\end{abstract}

\section{INTRODUCTION}

Well-learned and well-trained health care workers are an indispensable requirement of any healthcare system to meet the needs of patients. As a pre-requisite to this, it is the responsibility of medical education systems to impart knowledge, educate and train students, so that they become well prepared to provide high-quality care to patients ${ }^{1-3}$.

Formulating strategies that would engage students and provide them with effective education has always been a challenge to medical educators. Engagement in both academic and clinical settings has been associated with favourable outcomes in terms of learning and building confidence in students ${ }^{4}$. Over the years there has been a constant change over how new methods of education can be implemented in the model of classroom education in ways that can benefit the student ${ }^{5-6}$.

The methods previously used in a traditional classroom setup heavily depended on the presence of a tutor and students in an educational environment. However, advancements in technology have made it a possibility for the same education to be provided longdistance, be archived for later use and so, has increasingly become in demand worldwide 7,8 . They also show student preference for such novel methods of education over classroom learning, which allows access to the latest findings and employment of evidence-based knowledge. Virtual education uses computer-based learning on an online or offline network which can be accessed anytime and anywhere ${ }^{8}$.

Received on 24-03-2021

Accepted on 13-08-2021
However, this system has its drawbacks as well; first and foremost, it deems it necessary to have computer access to participate. Furthermore, creating a virtual education network for tutors as well as students comes at a high cost for the education system ${ }^{9}$. The program needs to be user-friendly, to allow students with limited computer skills to be able to take full advantage without any limitations ${ }^{9-10}$. Besides this, the effectiveness of such independent education is questionable, especially in the field of medicine where group discussions and peer interactions are necessary for knowledge and skill development. ${ }^{11-12}$ However, concluding the effectiveness of online and offline education is much difficult and has failed to conclude ${ }^{13}$

In developing countries like Pakistan and India, traditional learning is under much focus. But due to recent pandemic conditions due to COVID-19, where the whole world was affected, the education sector was also affected and there was a sudden and complete shift of learning from traditional to online teaching methods for which there was less preparedness by institutes as well as students.

This study aimed to compare the teaching methods i.e. traditional versus online teaching by measuring the learning outcomes of medical students.

\section{MATERIALS AND METHODS}

This retrospective study was conducted among pre-clinical medical students of the age group (18-21 years) of Dow International Medical College, Karachi after permission from IRB. The participants were divided into group $A$ and group B. Group A (traditional learning group) included 150 students who had learnt through traditional learning. Group $\mathrm{B}$ also comprised of 150 students who had learnt through 
online teaching methods in 2020. Traditional teaching was employed through large group teaching and small group teaching including problem-based learning ( $\mathrm{PBL})$, casebased learning (CBL), and tutorials while online teaching was carried out using MOODLE and ZOOM applications. Along with PowerPoint presentations, students were provided with tutorials, videos, and notes for a better understanding of topics during the e-learning session. All teaching faculty were trained for online teaching through three online courses of Coursera to provide a better teaching experience to students.

Both groups appeared in the same pattern of module tests i.e. Best Choice Questions (BCQs) to assess the theoretical knowledge. The exam comprised 100 marks for each module. The mean score of three module exams was compared between both groups. Group A had received traditional lectures in 2019 while group B received the same lectures from the same tutors but online in 2020. Mean scores of the Foundation module, Locomotor module (muscle and skeletal system), and Blood module were compared between both groups. The results were compiled and analyzed in SPSS 21.0. The mean difference was calculated from the independent ' $t$ ' test.

\section{RESULTS}

In the foundation module, the mean score of group $A$ was $50.12 \%$ and that of group B was $70.13 \%$. There was a significant difference in mean scores of both groups while a higher score was achieved by group $B$ who was involved in online learning in the year $2020(p<0.001)$. In the locomotor module mean score of group B $(53.72 \%)$ was significantly higher as compared to group A $(50.95 \%)$ with a significant p-value of 0.043. Meanwhile, in the blood module, the same pattern was seen in which group $B$ was able to achieve significantly higher score $(73.28 \%)$ as compared to group A $(50.70 \%)$ who was involved in traditional learning in the year 2019 with a p-value of 0.001 (Fig. 1).

Fig. 1: Mean score of group $A$ and group $B$ in module examinations



Foundation module Locomotor Module Blood Module aroup A $\square$ Group B

\section{DISCUSSION}

The first instance of distance learning came from the University of Chicago back in the 1800s when students and teachers used to connect with each other through written letters ${ }^{14}$. The online distance learning programs were started by many colleges and universities with online education programs in the second half of the $20^{\text {th }}$ century ${ }^{15}$.

The online education system has a huge number of issues not only for the faculty but mainly for the students ${ }^{16}$. These may include lack of training, lack of awareness, hesitation in adopting the change, poor internet connections, portal examination, and keeping the students involved in the lecture while looking at their computer screens ${ }^{17}$. Some universities already provided online classes but these classes were only limited ${ }^{18,19}$.

In countries like Pakistan, where traditional learning was the main tool for medical universities, sudden and complete shift to online education during COVID-19 pandemic was a new experience. The main focus of the study was to assess the learning outcomes of this online learning session-2020. As in the future, these results can help in modification of the learning and teaching strategies to deliver the knowledge in the best possible way.

Our study revealed significant higher scores achieved by online learning group which is accordance with Mitchell et $\mathrm{al}^{20}$ and Nourian et $\mathrm{al}^{21}$ who stated that students with frequent exposure to e-learning gained higher scores in exams. While Hugenholtz et $\mathrm{al}^{22}$ found no significant difference in e-learning and traditional learning outcomes for continuing medical education in theoretical exam scores of dental students. Moazami et $\mathrm{al}^{23}$ found similar results as our study, in which he compared mean exam scores of online and traditional learning groups and found e-learning had better results. Belcher et $\mathrm{al}^{24}$ also reported e-learning and easy access to educational content produced better results. Our results show online learning has produced better results as compared to traditional learning. This may be because of recent training of faculty for online teaching and students were provided with more reference materials along with books like videos, notes, and online discussion sessions.

Thurmond ${ }^{19}$ and Khatami et $\mathrm{al}^{25}$ reported better outcome of exam scores through traditional teaching and learning methods over virtual and the results are different from our study and may have different reasons like unavailability of the resources, required infrastructure, cost issues, decreased motivation, and interest of students. This was very first experience of online learning of pre-clinical medical students of our institute which proved to produce better results. In the future same technology-based learning can be used to impart online courses in the curriculum.

\section{CONCLUSION}

The score gained in online learning were higher than those who appeared in traditional learning. The results of this study imply that using online educational teaching and learning can lead to the promotion of educational level and enhancement of score levels in students. In the future, the same technology can be used to impart online courses to 
produce well-learned medical students which can serve the patients in a better way.

\section{Conflict of interest: Nil}

\section{REFERENCES}

1. Ellenbecker $\mathrm{CH}$, Fawcett J, Jones EJ, Mahoney D, Rowlands B, Waddell A. A staged approach to educating nurses in health policy. Policy Politics Nurs Prac2017;18(1):44-56.

2. Gubrud P, Spencer AG, Wagner L. From start-up to sustainability: a decade of collaboration to shape the future of nursing. Nurs Educ Perspec 2017;38(5):225-32.

3. Hofler L, Thomas K. Transition of new graduate nurses to the workforce: challenges and solutions in the changing health care environment. North Carolina Med J 2016;77(2):133-6.

4. Casuso-Holgado MJ, Cuesta-Vargas Al, Moreno-Morales N, Labajos-Manzanares MT, Barón-López FJ, Vega-Cuesta M. The association between academic engagement and achievement in health sciences students. BMC Med Educ 2013;13(1):33

5. Kerecsen L, Pazdernik TL. From mainframe to Web-based: 30 years of experience in computer-aided instruction of pharmacology. Naunyn-Schmiedeberg's Arch Pharmacol 2002;366(1):83-9.

6. Hendrickson WD, Panagakos F, Eisenberg E, McDonald J, Guest G, Jones P, Johnson L, Cintron L. Electronic curriculum implementation at North American dental schools. J Dent Educ 2004;68(10):1041-57.

7. Meckfessel S, Stühmer C, Bormann KH, Kupka T, Behrends $\mathrm{M}$, Matthies $\mathrm{H}$, et al. Introduction of e-learning in dental radiology reveals significantly improved results in final examination. J Craniomaxillofacial Surg 2011;39(1):40-8.

8. Browne L, Mehra S, Rattan R, Thomas G. Comparing lecture and e-learning as pedagogies for new and experienced professionals in dentistry. Br Dent J 2004;197(2):95-7.

9. Goodarzvand M, Esmaeili M. Information technology impression on education quality. J New Approaches Educ Adm 2012;2:1-24.

10. Zolfaghari M, Mehrdad N, Parsa Yekta Z, Salmani Barugh N, Bahrani $\mathrm{N}$. The effect of lecture and e-learning methods on learning mother and child health course in nursing students. Iranian J Med Educ2007;7(1):31-9.

11. Olmstead C. Using technology to increase parent involvement in schools. Tech Trends 2013; 57(6):28-37.
12. Cook DA, Levinson AJ, Garside S, Dupras DM, Erwin PJ, Montori VM. Internet-based learning in the health professions: a meta-analysis. JAMA 2008;300(10):1181-96.

13. Bartley SJ, Golek JH. Evaluating the cost-effectiveness of online and face-to-face instruction. J Educ Technol Soc 2004;7(4):167-75.

14. Sun $A$, Chen $X$. Online education and its effective practice: $a$ research review. J Infec Technol Res 2016; 15:157-90.

15. Preece J, Maloney-Krichmar D, Abras C. History of emergence of online communities. Encyclopedia Community 2003.

16. Mukhtar K, Javed K, Arooj M, Sethi A. Advantages, limitations and recommendations for online learning during COVID-19 pandemic era. Pak J Med Sci 2020;36:S27-31.

17. Farooq F, Rathore FA, Mansoor SN. Challenges of online medical education in Pakistan during COVID-19 Pandemic. JCPSP 2020;30:67-9.

18. Ahsan $\mathrm{F}$. List of Universities that provide online education in Pakistan. 2018.

19. Thurmond VA. Defining interaction and strategies to enhance interactions in Web-based courses. Nurse Educator 2003;28(5):237-41.

20. Mitchell EA, Ryan A, Carson O, McCann S. An exploratory study of web-enhanced learning in undergraduate nurse education. J Clin Nurs 2007; 16:2287-96.

21. Nourian A, Nourian A, Ebnahmadi A, Akbarzadeh Baghban A, Khoshnevisan $\mathrm{MH}$. Comparison of e-learning and traditional classroom instruction of dental public health for dental students of Shahid Beheshti Dental School during 2010-2011. J Dent School 2012;30(3):174-83.

22. Hugenholtz NI, De Croon EM, Smits PB, Van Dijk FJ, Nieuwenhuijsen K. Effectiveness of e-learning in continuing medical education for occupational physicians. Occupa Med 2008; 58(5):370-2.

23. Moazami F, Bahrampour E, Azar MR, Jahedi F, Moattari M. Comparing two methods of education (virtual versus traditional) on learning of Iranian dental students: a post-test only design study. BMC Med Educ 2014;14(1):1-5.

24. Belcher JV, Vonderhaar KJ. Web-delivered research-based nursing staff education for seeking Magnet status. JONA 2005;35(9):382-6.

25. Khatami A, Dehghan Nayery N, Ahmady F, Haghani H. The effect of web-based and traditional instructions on nurses' knowledge about AIDS. Iran J Med Educ 2011;11:140-8. 